\title{
Gênero Colobothea Lepeletier \& Audinet-Serville: novas espécies e sinonimia (Coleoptera, Cerambycidae, Lamiinae)
}

\author{
Miguel A. Monné1,2 \\ ${ }^{1}$ Museu Nacional, Universidade Federal do Rio de Janeiro, Quinta da Boa Vista, 20940-040, Rio de Janeiro-RJ, Brasil. \\ ${ }^{2}$ Pesquisador do CNPq.
}

\begin{abstract}
Genus Colobothea Lepeletier \& Audinet-Serville: new species and synonyms (Coleoptera, Cerambycidae, Lamiinae). The following new species are described: Colobothea denotata sp. nov. from Brazil (Amazonas), C. caramaschii sp. nov. from Venezuela and $C$. delicata sp. nov. from Costa Rica and Panamá. New synonymy proposed: C. albobimaculata Zajciw, 1961 and C. pseudosubcincta Zajciw, $1961=$ = . subcincta Laporte, 1840.
\end{abstract}

KEYWORDS. Cerambycidae; Colobothea; Colobotheini; new species; synonym.

RESUMO. Gênero Colobothea Lepeletier \& Audinet-Serville: novas espécies e sinonimia (Coleoptera, Cerambycidae, Lamiinae). Novas espécies descritas: Colobothea denotata, sp. nov. (Brasil, Amazonas), C. caramaschii sp. nov. (Venezuela) e C. delicata sp. nov. (Costa Rica e Panamá). Nova sinonimia proposta: C. albobimaculata Zajciw, $1961 \mathrm{e}$ C. pseudosubcincta Zajciw, $1961=$ C. subcincta Laporte, 1840.

PALAVRAS-CHAVE. Cerambycidae; Colobothea; Colobotheini; novas espécies; sinonímia.

Colobothea Lepeletier \& Audinet-Serville, 1825 apresenta distribuição Neotropical e engloba 118 espécies (Monné, 1995:8). Tavakilian (1997:135) considerou C. velutina Bates, 1865 sinônimo de Lamia macularis Olivier, 1792, reduzindo seu número a 117, das quais vinte se distribuem no México e na América Central (Giesbert, 1979).

Neste trabalho são descritas três espécies inéditas procedentes de Costa Rica, Panamá, Venezuela e Brasil (Amazonas) e é proposta a sinonimia de outra, amplamente distribuída no Brasil meridional, com base no estudo detalhado de 115 exemplares.

Abreviaturas utilizadas: JWCB, Jim Wappes collection, Bulverde, Texas, Estados Unidos; MNRJ, Museu Nacional, Universidade Federal do Rio de Janeiro, Rio de Janeiro, Brasil; MZSP, Museu de Zoologia, Universidade de São Paulo, São Paulo, Brasil; USNM, National Museum of Natural History, Washington, D. C., Estados Unidos.

\section{Colobothea denotata sp. nov.}

(Fig. 1)

Macho. Tegumento castanho-escuro a preto. Pubescência predominantemente preta. Pubescência branco-amarelada: na cabeça, linha mediana longitudinal no occipúcio e margem dos lobos inferiores dos olhos. No pronoto, duas linhas láterolongitudinais, a externa mais larga que a interna e expandida junto à borda posterior. Lados do protórax, junto às cavidades procoxais, epimeros, episternos e lados do metasterno com linha amarelo-esbranquiçada ininterrupta. Em cada élitro linha longitudinal mediana em ziguezague, que se projeta para as margens no terço basal, no meio e no terço distal. As linhas branco-amareladas de cada élitro delimitam mancha preta cordiforme sutural no terço basal e mácula subtriangular mediana. A pubescência branca recobre: metade basal dos antenômeros III e IV, os três quartos anteriores do antenômero VI, anel mediano nas tíbias e os tarsos. Prosterno, mesosterno e centro do metasterno com fina pilosidade cinzenta.

As antenas alcançam os ápices dos élitros no extremo distal do antenômero VI; antenômero V munido de curto espinho aguçado na extremidade ápico-interna. Protórax com lados subparalelos, sem tubérculo látero-basal; pontuação restrita à fileira junto às orlas anterior e posterior. Élitros com úmeros proeminentes, oblíquos na margem anterior; ápices truncados, ângulo externo projetado em espinho agudo. Quarto basal com pequenos grânulos setíferos; pontuação escassa e dispersa nos três quartos anteriores.

Lados dos protarsos com densos pelos pretos. Últimos urotergito e urosternito truncados na extremidade distal.

Dimensões, em mm, macho. Comprimento total, 13,0 - 19,0; comprimento do protórax, 2,5 - 4,0; maior largura do protórax, 3, 5 - 5, 0; comprimento do élitro, 10,0 - 13, 0; largura umeral, 4,0 $-6,0$;

Material-tipo. Holótipo macho, BRASIL, Amazonas: Rio Demiti "near little Homestead" ( $\left.0^{\circ} 35^{\prime} \mathrm{N}, 66^{\circ} 41^{\prime} \mathrm{W}\right)$, 28.VIII - 10.IX.1978, G. E. \& K. E. Ball col. (MNRJ). Parátipos, dois machos, mesmos dados. (MNRJ).

O Rio Demiti é afluente da margem esquerda do Rio Negro, próximo à fronteira com a Venezuela.

Discussão. Colobothea denotata sp. nov. tem em comum com C. brullei Gahan, 1889 a presença de espinho nas antenas dos machos, contudo em $C$. denotata está situado no antenômero $\mathrm{V}$ e em $C$. brullei no antenômero VI, além disso 
nesta última espécie o pronoto está ornado com três linhas brancas látero-longitudinais e $C$. denotata apresenta apenas duas linhas.

\section{Colobothea caramaschii sp. nov.} (Fig. 2)

Macho. Tegumento preto. Pubescência predominantemente cinzento-esbranquiçada, com brilho sedoso. A pubescência preta, muito curta e densa, reveste: ápice do escapo e os dois terços distais dos antenômeros IIIXI; três linhas longitudinais a cada lado do meio do pronoto, a intermediária com o dobro da largura da externa; mácula arredondada mediana e linha ínfero-lateral nos lados do protórax; escutelo (exceto margem); em cada élitro três linhas de contorno irregular, parcialmente interrompidas, a primeira da região subumeral, ascendente em direção ao meio da sutura, a segunda no início do terço distal e a terceira ante-apical, aproximada da margem; pequenas máculas arredondadas em toda a superfície elitral; anel ante-apical nos fêmures.

As antenas atingem os ápices dos élitros no terço distal do antenômero VI. Protórax com os lados divergentes para trás; pontuação do pronoto restrita às fileiras junto às margens anterior e posterior. Élitros com úmeros proeminentes, subretos na margem anterior. Ápices transversalmente truncados, com espinho aguçado no ângulo externo. Pontuaçao elitral muito pequena e dispersa, oculta pela densa pubescência cinzento-esbranquiçada. Último urotergito truncado; último urosternito semicircularmente emarginado.

Lados dos protarsos com pêlos longos e pretos. Coxas, centro do metasterno e dos segmentos abdominais, revestidos de densa e longa pilosidade amarelo-dourada, com brilho sedoso.

Dimensões, em mm, macho. Comprimento total, 19, 0; comprimento do protórax, 5, 0; maior largura do protórax, 3, 5; comprimento do élitro, 14, 0; maior largura umeral, 7, 0.

Material-tipo. Holótipo macho, VENEZUELA, Aragua: Rancho Grande (1100 m), 21.V.1980, J. A. Clavijo \& A. Chacon col. (MNRJ). Parátipo macho, VENEZUELA, Aragua: Parque Nacional Henri Pittier (Estación Biológica Rancho Grande), 7-13.VI. 1999, Ratcliffe, Jameson, Smith \& Villatoro col. (JWCB).

Discussão. A pubescência cinzento-esbranquiçada que predomina na superfície dorsal e a densa pilosidade amarelodourada que reveste a maior parte da superfície ventral permitem separar C. caramaschii sp. nov. de suas congêneres.

O epiteto homenageia o colega e amigo Ulisses Caramaschi (MNRJ), pela desinteressada colaboração na coleta e estudo de Cerambycidae.

\section{Colobothea delicata sp. nov.} (Figs 3, 4)

Macho. Tegumento preto. Pubescência predominante preta, aveludada. Pubescência branco-amarelada: na cabeça recobre os lados da fronte, uma linha mediana no vértice, bifurcada posteriormente; genas e faixa látero-longitudinal ininterrupta desde atrás dos lobos inferiores dos olhos até a margem posterior do metasterno; metade basal dos antenômeros III e IV e terço anterior dos antenômeros V, VI, VIII e X. Pronoto com uma linha estreita longitudinal a cada lado do meio e faixa lateral em cada lado do protórax. Desenho elitral como nas figuras 3 e 4 . Lados dos primeiros urosternitos visíveis cobertos com densa pubescência branco-amarelada e máculas pretas arredondadas.

As antenas alcançam as extremidades dos élitros no ápice do quinto antenômero. Protórax com os lados apenas divergentes para trás, sem tubérculo látero-basal. Pontuação do pronoto restrita à fileira junto à margem posterior. Élitros com pontos setíferos esparsos em toda a superfície. Ápices elitrais transversalmente truncados, ângulo externo projetado em curto espinho. Último urotergito truncado; último urosternito semicircularmente emarginado. Protarsos densamente pilosos nos lados.

Fêmea. As antenas alcançam as extremidades dos élitros no ápice do antenômero VI; último urotergito levemente entalhado, último urosternito transversalmente truncado; protarsos com escassos pelos longos laterais.

Dimensões, em mm, macho/fêmea. Comprimento total, 10,0$11,0 / 11,0 ;$ comprimento do protórax, 2,0-2,1/2,0; maior largura do protórax, 2,0-2,1/2,0; largura umeral, 3,0-3,2/3,4; comprimento do élitro, 7,0-7,3/7,2.

Holótipo macho, PANAMÁ, Panamá: Cerro Campana $(850 \mathrm{~m})$, 17.V.1993, E. G. Riley col. (USNM). Parátipos. COSTA RICA, Puntarenas: Monteverde, macho, 4-6.VI.1980, J. E. Wappes col. (MNRJ). PANAMÁ, Canal Zone: Barro Colorado Island, fêmea, 29.I.1997, Pickering \& Windsor col. (JWCB).

\section{Colobothea subcincta Laporte, 1840}

(Figs 5-7)

Colobothea subcincta Laporte, 1840:491; Bates, 1865:224; Redtenbacher, 1867:178 (distr.); Zikán \& Zikán, 1944:40 (distr.); Zajciw, 1958:20 (distr.); Buck, 1959:607 (distr.); Zajciw, 1962:291; 1972:68 (distr.); 1974:47 (hosp.); Monné, 2002: 8 (cat.).

Colobothea albobimaculata Zajciw, 1961: 385, fig. 1; 1974: 79 (distr.); Julio et al., 2000: 34 (holótipo). Syn. nov.

Colobothea pseudosubcincta Zajciw, 1961: 387, fig. 2; 1962: 291; Julio et al., 2000: 34 (holótipo). Syn. nov.

Os caracteres listados por ZAJCIW (1961) para separar $C$. albobimaculata de C. subcincta, referentes às "genas mais longas que o diâmetro dos olhos" e "tubérculos laterais do protórax mais obsoletos", são apenas ligeiras modificações intraespecíficas que se diluem ao examinar 115 exemplares.

O padrão de desenho elitral varia consideravelmente; a mancha arredondada ante-apical de nítida pubescência branca aparece menos contrastante e entremeada com pontos pretos em exemplares da mesma localidade (Linhares, Espírito Santo).

As mesmas considerações podem ser feitas para $C$. pseudosubcincta, tanto em relação à proporção entre dimensões dos olhos e das genas, quanto ao desenvolvimento dos tubérculos laterais do protórax. A proporção entre área 

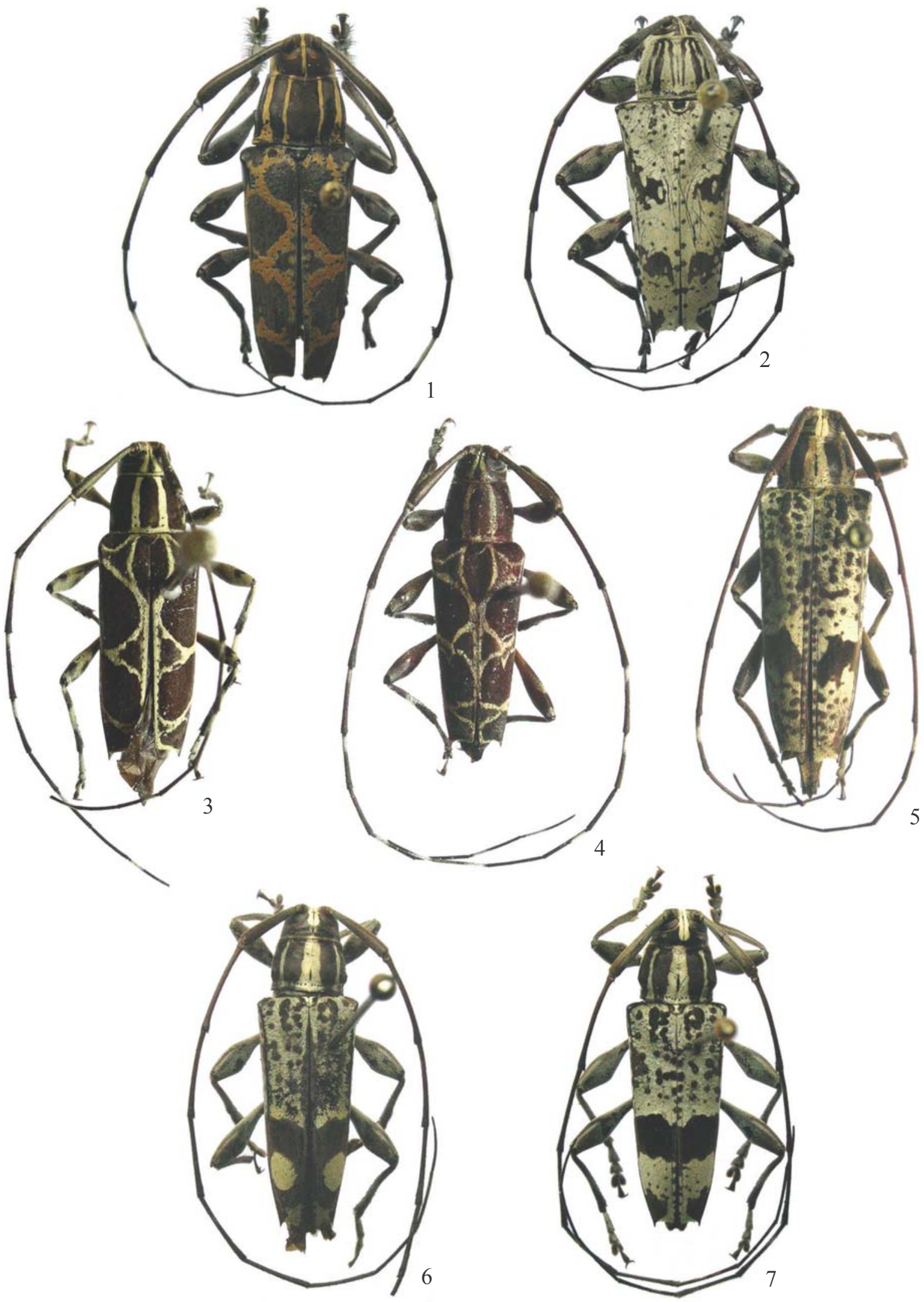

Figs. 1-7. 1, Colobothea denotata sp. nov., comprimento, 19,0 mm. 2, Colobothea caramaschii sp. nov., comprimento, 19,0 mm. 3-4, Colobothea delicata sp. nov., comprimento 11,0 mm. 5-7, Colobothea subcincta Laporte, 1840, comprimento, 16-18 mm. 
elitral ocupada por pubescência preta e branca varia consideravelmente, existindo exemplares quase totalmente brancos.

Material examinado. BRASIL. Espirito Santo: Linhares, 3 machos, 3 fêmeas. (Parque Sooretama), 5 machos, 3 fêmeas. Mun. de São Francisco (Córrego do Itá), 2 machos, 2 fêmeas (holótipo macho de $C$. albobimaculata). S. M. Jetibá, fêmea. Minas Gerais: Barreira do Piquete (Serra da Mantiqueira), macho. Poços de Caldas, 7 machos, 9 fêmeas. Rio de Janeiro: Rio de Janeiro, macho. (Corcovado), 11 machos, 10 fêmeas.( Estrada do Sumaré), fêmea. (Floresta da Tijuca), 2 machos, 3 fêmeas. Itatiaia, 3 fêmeas. Nova Friburgo, fêmea. Teresópolis, fêmea. São Paulo: São Paulo, fêmea. (Cantareira), 3 machos, 2 fêmeas. (Jabaquara), macho, 2 fêmeas. Peruíbe, macho. Rio Claro, macho. Paraná: Barigui, macho, fêmea. Curitiba, 2 machos, fêmea. Rio Negro, fêmea. Santa Catarina: Corupá, 2 machos. Joinville, macho. Mafra, 3 machos, 4 fêmeas (holótipo macho de C. pseudosubcincta). Nova Teutonia, macho, fêmea. Pinhal, macho. Rio Júlio, fêmea. Rio Natal, macho, fêmea. Rio Negrinho, 2 machos. São Bento do Sul, macho. (Rio Vermelho), macho.

Agradecimentos. A Jim E Wappes (JWCB) pela remessa de material para identificar e a Marcela L. Monné e José Ricardo Miras Mermudes (MZSP), pelas fotografias.

\section{REFERÊNCIAS}

Bates, H. W. 1865. Contributions to an insect fauna of the Amazon Valley. Coleoptera: Longicornes. The Annals and Magazine of Natural History 15: 213-225.

Buck, P. 1959. Cerambycidae in der Sammlung des Instituto Anchietano de Pesquisas. Pesquisas 3: 577-609.

Giesbert, E. F. 1979. A review of the Mexican and Central American species of Colobothea Serville (Coleoptera, Cerambycidae). The Coleopterists Bulletin 33: 415-438.

Julio, C. E. A., Giorgi, J. A. \& Monné, M. A. 2000. Os tipos primários de Cerambycidae (Coleoptera) da coleção do Museu Nacional - Rio de Janeiro. Publicações Avulsas do Museu Nacional 84: 1-54.
Laporte, F. L. N. 1840. Histoire Naturelle des Insectes Coléoptères. Paris, Duménil,v. 2, 563 p.

Monné, M. A. 1995. Catalogue of the Cerambycidae (Coleoptera) of the Western Hemisphere. Part XIX. Subfamily Lamiinae: Tribes Elytracanthini, Cyrtinini, Colobotheini, Tetraopini, and Saperdini. São Paulo, Sociedade Brasileira de Entomologia, $94 \mathrm{p}$.

Monné, M. A. 2002. Catalogue of the Neotropical Cerambycidae (Coleoptera) with known host plant - Part IV: Subfamily Lamiinae, Tribes Batocerini to Xenofreini. Publicações Avulsas do Museu Nacional 94: 1-92.

Redtenbacher, L. 1867. Coleopteren In: Reise des österreichischen Fregatte Novara und die Erde in den Jahren 1857, 1858, 1859, unter der befehlen des Commodore $B$. von Wüllerstorf- Urbair. Wien, Zoologischer Theil, Zweiter Band, $249 \mathrm{p}$.

Tavakilian, G. L. 1997. Nomenclatural changes, reinstatements, new combinations, and new synonymies among American Cerambycids (Coleoptera). Insecta Mundi 11: 129-139.

Zajciw, D. 1958. Fauna do Distrito Federal XLVIII. Contribuição para o conhecimento dos longicórneos de Rio de Janeiro (Coleoptera, Cerambycidae). Boletim do Museu Nacional (n.s.) Zoologia, 189: $1-26$.

Zajciw, D. 1961. Novas espécies neotrópicas de "Colobothea" Serville, 1825 (Coleoptera, Cerambycidae, Lamiinae). Revista Brasileira de Biologia 21: 385-390.

Zajciw, D. 1962. Cinco novas espécies neotrópicas de Colobothea Serville, 1825 (Coleoptera, Cerambycidae, Lamiinae) com chave para determinação das espécies sul-brasileiras. Anais da Academia Brasileira de Ciências 4: 281-293.

Zajciw, D. 1972. Contribuição para o estudo da fauna dos longicórneos do Parque Nacional do Itatiaia (Coleoptera, Cerambycidae). Brasil Florestal 3: $40-72$.

Zajciw, D. 1974. Contribuição para o estudo da fauna dos longicórneos (Coleoptera, Cerambycidae) das florestas do Estado do Espírito Santo e principalmente da Reserva Biológica Soôretama. Boletim Técnico do Instituto Brasileiro de Desenvolvimento Florestal 4: 37-91.

Zikán, J. F. \& Zikán, W. 1944. A inseto-fauna do Itatiaia e da Mantiqueira. Boletim do Ministerio de Agricultura 33: 1-50.

Recebido em 28.XII.2004; aceito em 12.IV.2005 